\title{
TRANSFORMACIONES EN LAS FINANZAS PÚBLICAS A PARTIR DE LA CONSTITUCIÓN DE 1991
}

Gerardo Rodríguez-Estupiñan Universidad de Cartagena Colombia

Gerardo Rodríguez-Morris

Universidad de Cartagena

Colombia 
Panorama Económico, Vol. 27 - No. 2 (Abril - Junio de 2019), pp. 410-428

Gerardo Rodríguez Estupiñan

Gerardo Rodríguez Morris

JEL: H70, H71, H72

\title{
Transformaciones en las finanzas públicas a partir de la Constitución de 1991
}

\begin{abstract}
Resumen
Los objetivos propuestos por la constituyente de 1991 con el Estado Social de Derecho de satisfacer necesidades básicas, generó transformaciones especialmente en el manejo de las finanzas públicas. A pesar de los avances en la disminución de la pobreza, veinticinco años después de la puesta en marcha de esta nueva Constitución se han presentado reformas que pretenden generar una mayor equidad social y económica. Los resultados han sido todo lo contrario: Colombia se constituye como el segundo país más inequitativo en América Latina, las finanzas entraron a depender del sector minero-energético cuyos precios se caracterizan por su alta volatilidad a nivel internacional, y que pueden generar una enfermedad holandesa con efectos que estimulan la desindustrialización y empleo precario. El papel de las políticas públicas reflejado en el presupuesto nacional y territorial, es fundamental para cerrar brechas regionales. De ahí la importancia de entender la evolución de las transferencias territoriales y de las regalías como principales bases de la descentralización fiscal, de analizar los sistemas tributarios cada vez más regresivos y de la importancia que llegaron a tener los ingresos petroleros en las finanzas públicas de Colombia.
\end{abstract}

Palabras clave: Finanzas Públicas, Transferencias, Regalías, regresividad tributaria, descentralización fiscal.

\section{Transformations des finances publiques depuis la Constitution de 1991}

\section{Résumé}

Les objectifs proposés par le constituant de 1991 à l'Etat de droit social pour satisfaire les besoins fondamentaux, ont généré des transformations notamment dans la gestion des finances publiques. Malgré les progrès réalisés dans la réduction de la pauvreté, vingt-cinq ans après la mise en œuvre de cette nouvelle Constitution, des réformes ont été présentées qui visent à générer une plus grande équité sociale et économique. Les résultats ont été inversés: la Colombie est le deuxième pays le plus inéquitable d'Amérique latine, les finances sont devenues dépendantes du secteur de l'énergie minière dont les prix se caractérisent par leur forte volatilité au niveau international, et qui peuvent générer une maladie hollandaise avec des effets qui stimulent la désindustrialisation et l'emploi précaire. Le rôle des politiques publiques reflété dans le budget national et territorial est essentiel pour combler les écarts régionaux. D'où l'importance de comprendre l'évolution des transferts fonciers et des redevances comme principales bases de la décentralisation fiscale, d'analyser les régimes fiscaux de plus en plus régressifs et de l'importance que les revenus pétroliers ont pris dans les finances publiques de la Colombie.

Mots clés: Finances publiques, transferts, redevances, régressivité fiscale, décentralisation fiscale.

\section{Transformations in public finances since the 1991 Constitution}

\begin{abstract}
The objectives proposed by the 1991 constituent with the Social Rule of Law to satisfy basic needs, generated transformations especially in the management of public finances. Despite the progress made in reducing poverty, twenty-five years after the implementation of this new Constitution, reforms have been presented that seek to generate greater social and economic equity. The results have been the opposite: Colombia constitutes the second most inequitable country in Latin America, finances came to depend on the mining-energy sector whose prices are characterized by their high volatility at the international level, and which can generate a Dutch disease with effects that stimulate deindustrialization and precarious employment. The role of public policies reflected in the national and territorial budget is essential to close regional gaps. Hence the importance of understanding the evolution of land transfers and royalties as the main bases of fiscal decentralization, of analyzing the increasingly regressive tax systems and of the importance that oil revenues came to have in the public finances of Colombia.
\end{abstract}

Keywords: Public Finance, Transfers, Royalties, tax regressivity, fiscal decentralization. 


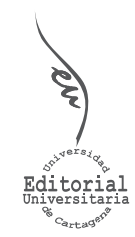

Artículo de Reflexión

\section{Transformaciones en las finanzas públicas a partir de la Constitución de 1991}

INFORMACIÓN DEL ARTíCULO

Recepción del artículo: 05/01/2019

Concepto de evaluación: 09/02/2019

Aceptación del artículo: 13/03/2019
Gerardo Rodríguez-Estupiñan'

Universidad de Cartagena, Colombia

Gerardo Rodríguez-Morris Universidad de Cartagena, Colombia

\section{INTRODUCCIÓN}

Al ser el Estado el principal actor en la toma de decisiones dirigiendo la actividad económica del país, es pertinente analizar sus fuentes de ingresos, las cuales financiarán toda la estructura política, económica y social que ejerce sobre el bienestar de una población. En forma general y en orden de importancia, estos recursos provienen de: Impuestos, deuda pública, venta de activos del Estado y emisión de dinero.

En periodos de crisis, como la presentada en 1929 causada por insuficiencia de demanda y por falta de estímulos propios de esta fase del ciclo para la inversión, la deuda pública se convierte en una fuente importante de ingresos para el Estado, y las finanzas públicas sufren una transformación al pasar de presupuestos equilibrados contablemente a presupuestos en desequilibrio; es decir al existir deuda, se demuestra cómo esta empieza a cumplir un papel de financiación de la economía como lo analizó Keynes: la inversión pública reactiva la economía, la fuente de la inversión fue la emisión de bonos (títulos de deuda pública), dando paso de esta forma a un gasto público dinámico generador de demanda efectiva. La teoría de Keynes deja como legado que el déficit fiscal, es decir, la diferencia negativa entre los gastos y los ingresos públicos financia la economía llevándola a un equilibrio con desempleo (Ramirez, 2008).

En la década de los 70 con el surgimiento de estanflación en la economía se pone en duda el pensamiento de Keynes, dando lugar al nacimiento de una nueva generación de economistas entre los que sobresalen aquellos considerados padres del neoliberalismo como Hayek y Friedman. Con ellos entra en furor nuevamente el libre mercado como mejor asignador de recursos y las privatizaciones empiezan a ocupar un lugar estratégico como fuente de financiación del Estado. 
En Colombia el principal instrumento de análisis de las finanzas públicas es el Presupuesto General de la Nación. Su marco normativo se establece en el Estatuto Orgánico del Presupuesto (Decreto 111 de 1996) que toma como base el título XII de la Constitución, en la cual se establece la existencia de un presupuesto de rentas y uno de gastos o ley de apropiación; según el artículo 346 de la Constitución Política, el Gobierno formulará anualmente el presupuesto de rentas y ley de apropiaciones, que será presentado al Congreso dentro de los primeros diez días de cada legislatura. En el capítulo V, se esboza el presupuesto de rentas y ley de apropiaciones, que deberá elaborarse, presentarse y aprobarse dentro de un marco de sostenibilidad fiscal y corresponder al Plan Nacional de Desarrollo. En la Ley de Apropiaciones no podrá incluirse: partida alguna que no corresponda a un crédito judicialmente reconocido, un gasto decretado conforme a ley anterior, a uno propuesto por el Gobierno para atender debidamente el funcionamiento de las ramas del poder público, al servicio de la deuda, o destinado a dar cumplimiento al Plan Nacional de Desarrollo.

A pesar de que las rentas y recursos de capital de la Nación comprenden los ingresos corrientes, los recursos de capital, las contribuciones parafiscales y los fondos especiales como lo contempla el artículo 27 y 29 del decreto 111 de 1996, este escrito se concentrará principalmente en los ingresos corrientes los cuales son ingresos permanentes al estar formados por ingresos tributarios, ingresos de la seguridad social, ingresos petroleros e ingresos no tributarios, describiendo las transformaciones experimentadas por las finanzas públicas en Colombia a partir, principalmente, de la constitución de 1991, resumidas en: descentralización fiscal, la regla fiscal aplicada en el año 2011, la transformación en el manejo de las regalías a partir de la ley 1530 del 2012, las sucesivas reformas tributarias, la volatilidad en el precio del petróleo.

\section{DEL CENTRALISMO A DESCENTRALIZACION FISCAL}

Las finanzas públicas de Colombia experimentan una total transformación a partir de la puesta en marcha de la Constitución política de 1991 al pasar de un manejo centralista a uno de descentralización fiscal. Entre 1930 y 1979 la participación del Estado central en el total de las recaudaciones tributarias aumentó de 54\% a 84\%, nivel que se mantenía a comienzos de los años noventa (Aghón, 2001). Es así como de acuerdo con la Dirección de Apoyo Fiscal (DAF), en 1993 cerca del 13\% de los ingresos corrientes del Gobierno Central eran transferidos a los gobiernos subnacionales, en el 2000 este porcentaje llegó al 49\% (Ministerio de Hacienda y Crédito Público, 2009)

De igual forma la DAF explica cómo la descentralización fiscal adquirió un carácter político-estatal, es decir que se crea un entorno de mayor autonomía política-territorial a través de la elección popular de gobernadores y la creación de nuevos departamentos. Las transferencias adquieren el carácter de rentas de propiedad exclusiva de los departamentos y municipios, caracterizadas por darle una mayor prioridad a la financiación de servicios de educación, salud y saneamiento básico. De igual forma, las finanzas territoriales se fortalecieron con las regalías por la explotación de recursos naturales no renovables y el sistema de cofinanciación que permite transferencias adicionales de la nación, condicionadas a contrapartidas por gobernaciones y alcaldías para financiar proyectos de inversión. 
La Constitución Política, a través de los artículos 287, 300, 313, 338 y $363^{2}$ otorga la autonomía tributaria a los entes territoriales, quedando facultados para cobrar impuestos que son determinados tanto es sus bases gravables como en sus tarifas por leyes nacionales. Las dificultades, especialmente en departamentos, con la puesta en marcha de este mandato constitucional, se presentan porque sus impuestos son de difícil control y recaudo, acompañados de estatutos tributarios engorrosos y sin claridad en las bases gravables. Es así como municipios y departamentos continúan teniendo como principal fuente de ingresos las transferencias que han crecido en mayor proporción a los ingresos tributarios (Rodríguez Estupiñan, 2012).

La descentralización fiscal puesta en marcha por la nueva Constitución en la década de los 90 lleva a la economía nacional y territorial a experimentar déficits fiscales, es decir, se aumenta el gasto en mayor proporción al ingreso: entre 1990 y 1999 los ingresos tributarios del Gobierno Nacional pasaron del 7.8\% del PIB a 10.6\% del PIB, mientras que en los gobiernos subnacionales los recaudos tributarios aumentaron de $1.8 \%$ del PIB a 2.9\% del PIB. El crecimiento del recaudo tributario de las entidades territoriales resultó inferior al de las transferencias nacionales (por el llamado 'situado fiscal'). Durante el periodo 1990-1999 como porcentaje del PIB las transferencias nacionales crecieron tres puntos porcentuales y los tributos territoriales un punto porcentual (Ministerio de Hacienda y Crédito Público, 2009).

Ilustración 1. Ingresos tributarios por niveles de gobierno \%PIB

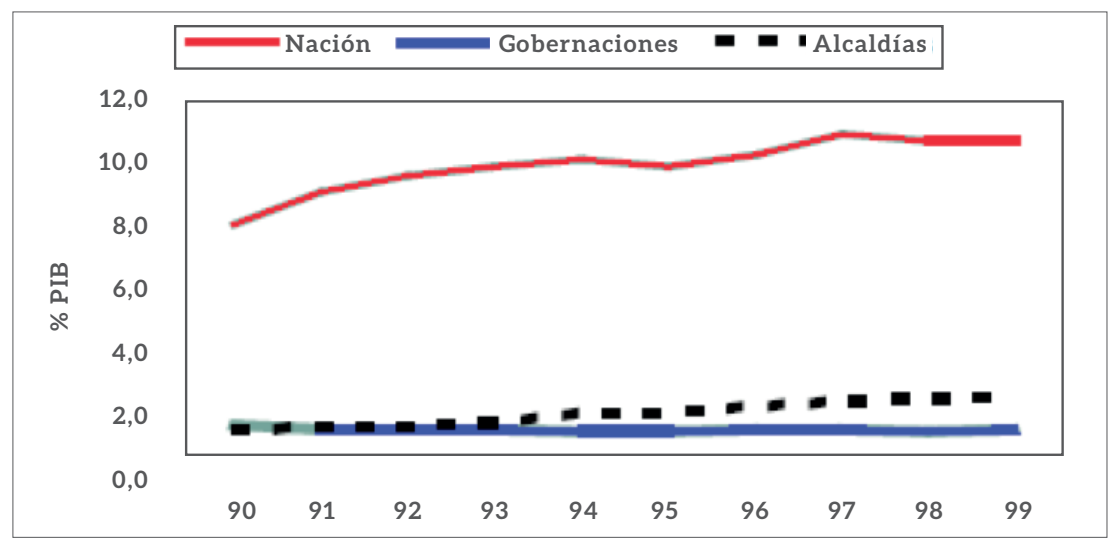

Fuente: Banco de la República y Confis.

2. 287: Se ocupa de las facultades que en desarrollo de la autonomía tienen las entidades territoriales, incluida la de establecer tributos. 300 y 313: Describen las atribuciones de las asambleas, departamentos y concejos municipales en decretar tributos, entre otros. 338: Delimita quiénes pueden decretar tributos. 363: Enmarca los principios que rige el sistema impositivo en Colombia. 
Ilustración 2. Tributarios territoriales y transferencias nacionales \%PIB

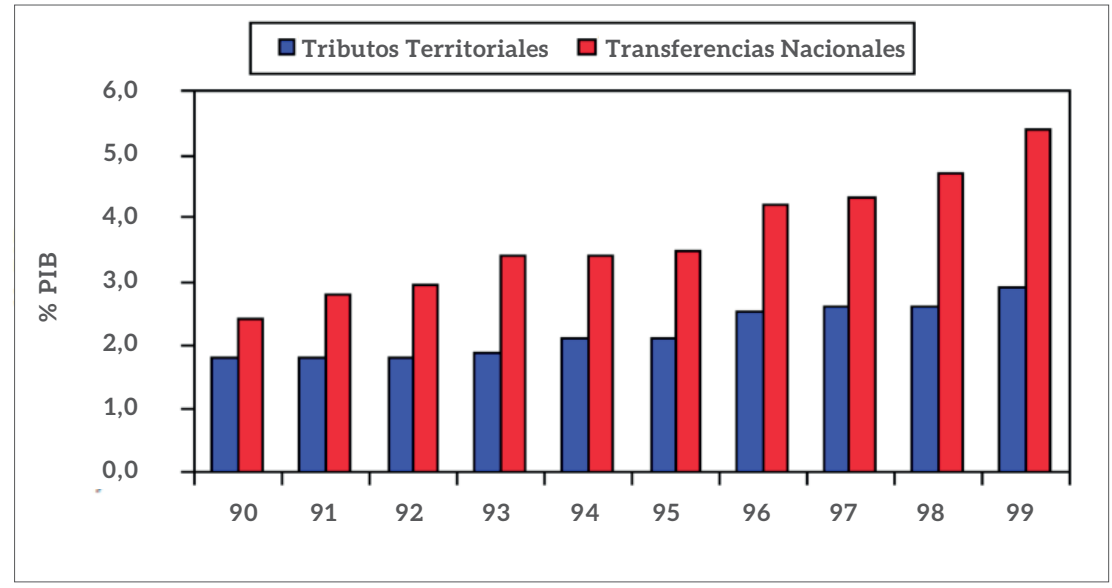

Fuente: Banco de la República y Confis.

En 1999, la economía colombiana experimenta una crisis explicada en gran parte por los resultados anteriormente mencionados. El deterioro fiscal territorial se agudizó como en el mismo documento citado por la DAF se demuestra, al explicar cómo más de la mitad de las gobernaciones y la tercera parte de municipios del país presentaban balances corrientes negativos y dependían del crédito para financiarse. Como resultado, muchas entidades territoriales entraron en cese de pagos de créditos y de sus nóminas tanto de personal activo como de pensionados (Tabla 1).

Tabla 1.

Finanzas públicas territoriales

\begin{tabular}{|c|c|c|c|c|c|}
\hline $\begin{array}{l}\text { Entidades } \\
\text { territoriales }\end{array}$ & $\begin{array}{c}\text { Deuda interna } \\
\text { causada y } \\
\text { no pagada }\end{array}$ & $\begin{array}{l}\text { Mesadas } \\
\text { pensionales } \\
\text { atrasadas }\end{array}$ & $\begin{array}{c}\text { Salarios y } \\
\text { prestaciones } \\
\text { sociales atrasados }\end{array}$ & Otros & Total \\
\hline Departamentos & 202,298 & 23,818 & 301,153 & 135,752 & 663,02 \\
\hline $\begin{array}{l}\text { Municipios } \\
\text { capitales }\end{array}$ & 81,660 & 9,905 & 387,704 & 160,033 & 639,30 \\
\hline $\begin{array}{l}\text { Restos } \\
\text { Municipios }\end{array}$ & 55,825 & 17,198 & 395,843 & 171,719 & 640,59 \\
\hline Total & 339,783 & 50,921 & $1,084,700$ & 467,504 & $1,942,908$ \\
\hline
\end{tabular}

Fuente: Elaboración propia con base en datos de la DAF del Ministerio de Hacienda y Crédito Público. 
El Gobierno central propone una serie de reformas para superar la crisis concentrándose en el recorte del gasto, siendo el más grande aquel que se destinaba a las regiones a través de las transferencias (Situado Fiscal) modificando la evolución creciente que se generaría en la participación de los municipios y departamentos en los ingresos corrientes de la nación que a partir del 2002 serían del 42,5\% como lo determinaba el artículo 358 de la C.P. Es así como se crean una serie de normas de ajuste fiscal que le dan nuevamente un viraje a las finanzas públicas colombianas:

a) Sistema General de Participación (SGP) reglamentado a través de la ley 715 de 2001, la ley 1176 del 2007 y la ley 1122 del 2017 que recogen no solo el situado fiscal, sino la transformación de la participación de los entes territoriales (E.T) en los ingresos corrientes de la Nación. El crecimiento anual del SGP se desvincula totalmente de dichos ingresos, y pasa a ser calculado según la inflación anual más dos puntos en los primeros cuatro años y $2.5 \%$ en los restantes. También se estableció una bonificación para las regiones en el caso de que a la economía le fuera muy bien y creciera más del 4\%. Según el acto legislativo 04 de 2007 que modifica los artículos 356 y 357 de la CP, a partir del 2008 estos recursos crecerán de la siguiente forma (Tabla 2):

Tabla 2.

Sistema General de Participación (SGP)

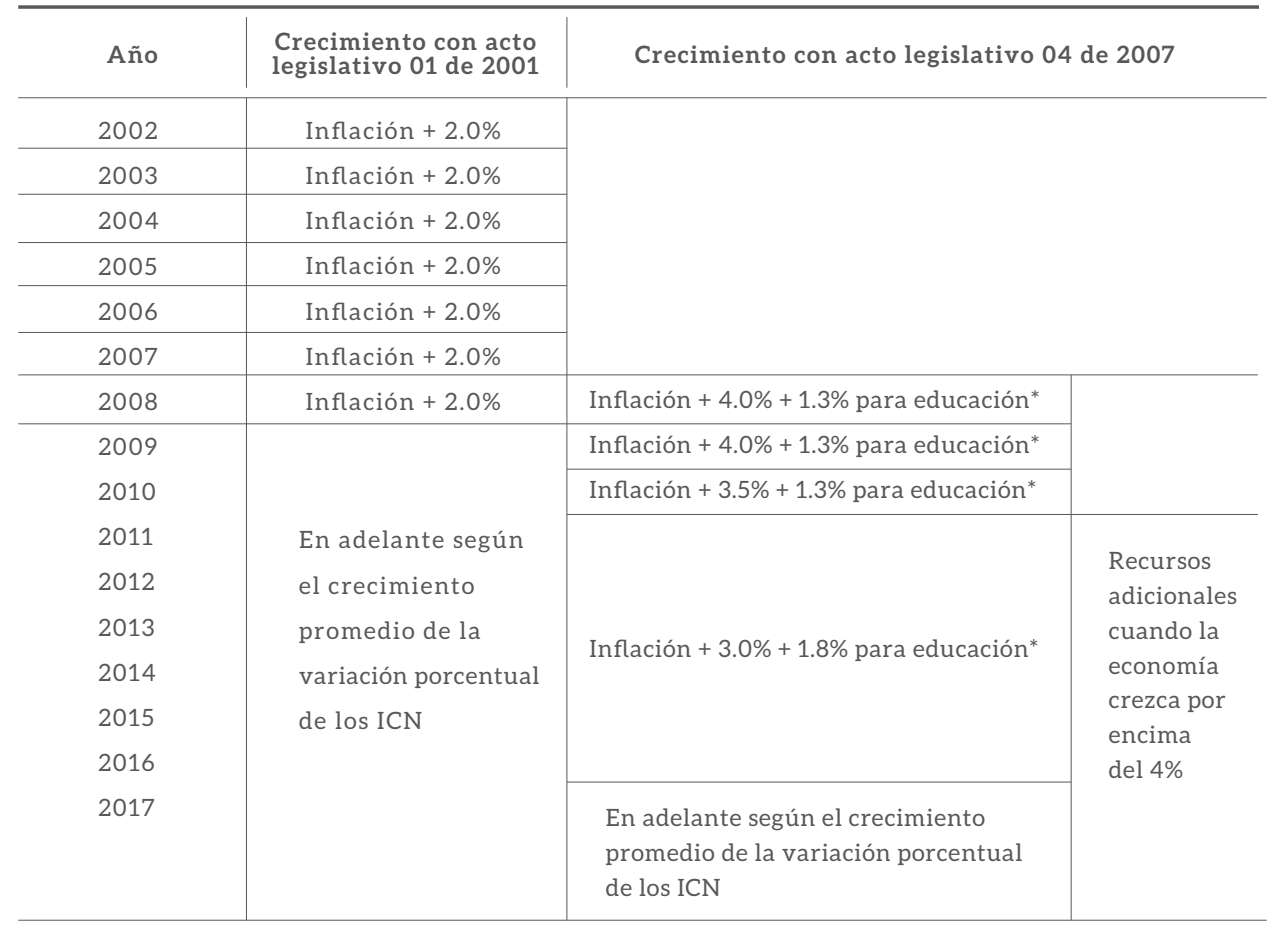

*Estos recursos no hacen base de cálculo para el año siguiente

Fuente: DNP 2010. 
b) Ley 617 del 2000, que marca límites al gasto de funcionamiento e impulsa la reestructuración de la deuda interna territorial mediante el otorgamiento de garantías de la Nación. A través de esta ley junto con el decreto reglamentario 192 de 2001 promueve un programa de saneamiento fiscal y financiero con el cual se compromete la entidad territorial a establecer su solidez económica y financiera.

c) Ley 549 de 1999, con el propósito de solucionar el creciente pasivo pensional territorial se crea el FONPET (Fondo Nacional de Pensiones de Entes Territoriales)

d) Ley 550 de 1999, para la reestructuración de pasivos corrientes a través de un acuerdo con sus acreedores.

e) Ley 819 de 2003, creando el Marco Fiscal de Mediano Plazo, con el objeto de promover la responsabilidad de las entidades territoriales en un periodo de 10 años para la toma de decisiones fiscales en la elaboración de los presupuestos anuales.

Los resultados positivos por la puesta en marcha de este paquete de normas se sintieron en los entes territoriales. Como bien lo explica la DAF, los resultados de estas medidas llevaron a que durante el periodo 2000-2007 los ingresos corrientes de los departamentos aumentara en promedio un 12.8\% anual, en términos reales. Los ingresos tributarios y no tributarios tuvieron un crecimiento por encima del de las transferencias. Y las regalías, que se constituyen como principal ingreso de capital, aumentaron en casi un 18\% promedio anual (Tabla 3).

Tabla 3.

Ingreso total gobernaciones en millones de pesos

\begin{tabular}{|c|c|c|c|c|c|}
\hline & 2000 & 2003 & 2007 & $\begin{array}{c}\text { Variación Real } \\
2007 / 2000\end{array}$ & $\begin{array}{c}\text { Variación Real } \\
\text { Promedio Anual } \\
2007 / 2004\end{array}$ \\
\hline Ingresos corrientes & 5.748 .483 & 7.886 .696 & 11.842 .505 & $106 \%$ & $12.8 \%$ \\
\hline Tributarios & 1.723 .193 & 2.427 .778 & 3.894 .153 & $126 \%$ & $14.6 \%$ \\
\hline No tributarios & 291.542 & 324.071 & 792.351 & $171.8 \%$ & $18.1 \%$ \\
\hline Transferencias & 3.733 .748 & 5.134 .847 & 7.156 .011 & $91.7 \%$ & $11.5 \%$ \\
\hline Ingresos de capital & 979.874 & 1.445 .462 & 2.306 .908 & $15.3 \%$ & $12.8 \%$ \\
\hline Regalías & 653.845 & 1.123 .042 & 1.756 .420 & $168.6 \%$ & $17.9 \%$ \\
\hline $\begin{array}{l}\text { Rendimientos } \\
\text { financieros }\end{array}$ & & & 238.593 & & \\
\hline Otros & 326.029 & 322.420 & 311.895 & $(4.3 \%)$ & $(0.7 \%)$ \\
\hline Crédito & 0 & 95.879 & 461.272 & & \\
\hline Recursos del balance & 147.216 & 254.781 & 3.196 .597 & $2071 \%$ & $67 \%$ \\
\hline Ingresos totales & 6.728 .357 & 9.428 .037 & 17.807 .282 & $164.7 \%$ & $17.6 \%$ \\
\hline
\end{tabular}

Fuente: DAF con datos de Secretarías de Hacienda. 
En cuanto a los municipios, los ingresos corrientes aumentaron en 14\% promedio anual en términos reales, cifra superior a la de gobernaciones, gracias al dinamismo de los ingresos de recaudo propio (tributarios y no tributarios) y transferencias nacionales. Estas últimas también fueron superiores frente a las gobernaciones debido al cumplimiento del mandato constitucional y legal de delegar competencias y recursos a nivel local, especialmente en salud y educación (Tabla 4).

Tabla 4.

Ingresos Totales Municipales

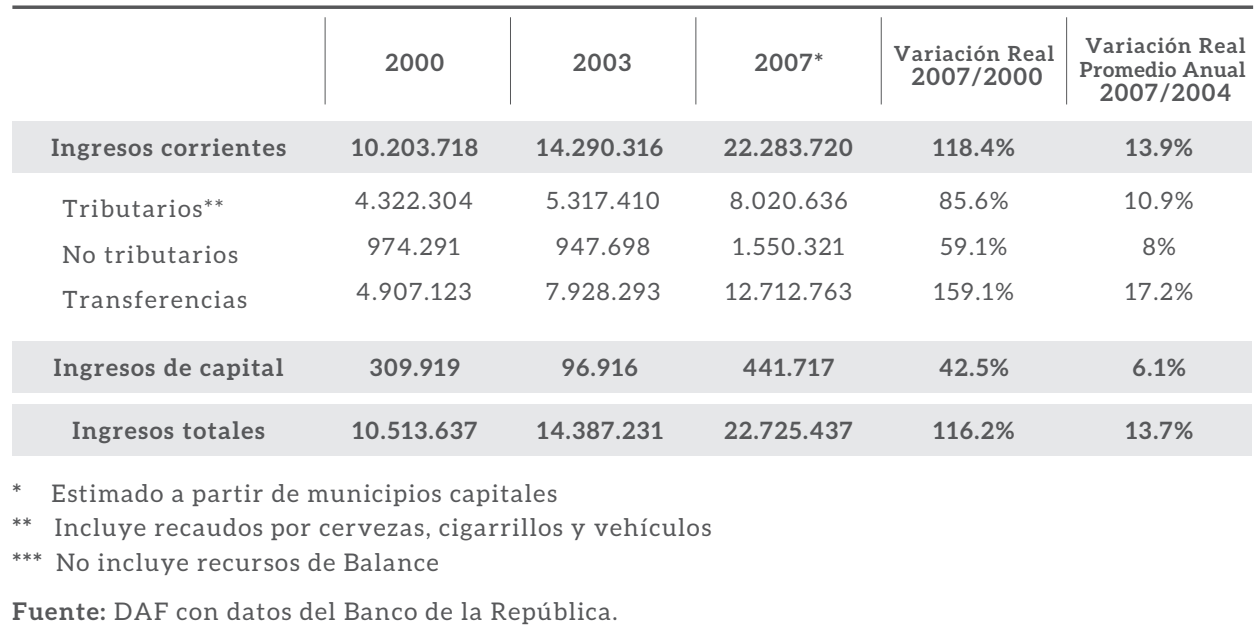

\section{REGLA FISCAL}

La preocupación demostrada por la legislación colombiana para controlar la política fiscal de los gobiernos de turno se ha reflejado especialmente en la década de los 90 restringiendo las posibilidades de endeudamiento de los entes territoriales con la ley 358 de 1997. Posteriormente se busca disminuir discrecionalidad en las decisiones económicas a través de la ley 617 del 2000 por el excesivo gasto de funcionamiento en que incurrían los entes territoriales.

Frente al deterioro fiscal de la economía colombiana se hace necesario generar una disciplina fiscal en las decisiones económicas por parte del Gobierno Central que garantice el cumplimiento a largo plazo de aquellos compromisos contraídos por el Estado. Surge la adopción de una Regla Fiscal como directriz de política económica para establecer el derecho a la sostenibilidad fiscal y no poner en riesgo los fines que se pretenden alcanzar con el estado social de derecho consagrado en la constitución política. Es así como el Acto Legislativo 03 de 2011 elevó a rango constitucional la sostenibilidad fiscal del Estado, dándole desarrollo legal con la ley 1473 de 2011 fijando dicha regla fiscal como política de Estado.

La Regla Fiscal, acogida por el gobierno Santos, propone que se debe mantener una senda decreciente para el déficit fiscal estructural de manera que en el 2014 este sea igual o 
inferior a 2.3\% del PIB, en el 2018 de máximo 1.9\% del PIB, y en el 2022 del 1\% del PIB o menos. Esa dinámica llevaría a que la deuda pública pasara de 38\% del PIB en el 2010 a $34 \%$ en el 2014 y a 30\% en el 2020 (Steiner, 2014).

Ilustración 3. Balance Primario del Sector Público Colombiano

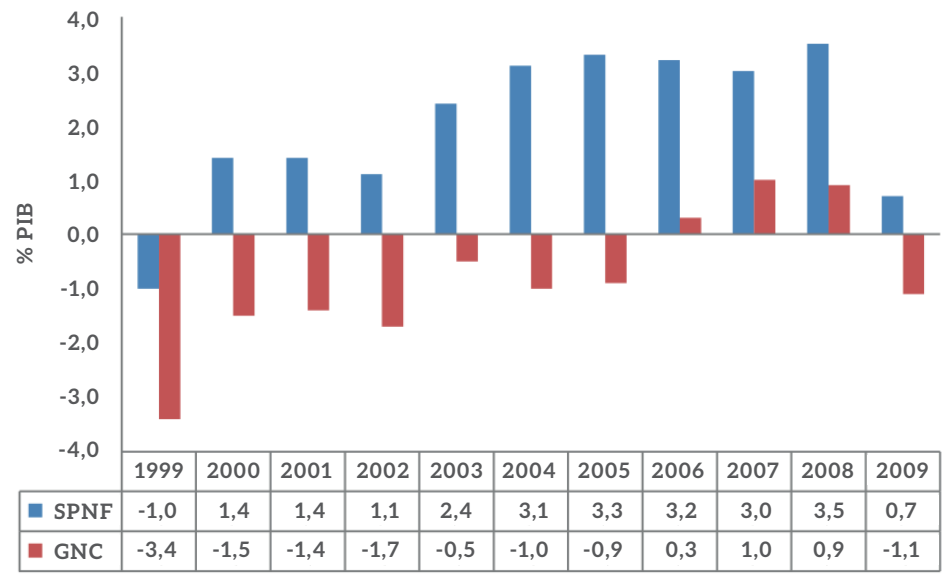

Fuente: Elaboración propia con base en datos de Comité Técnico Interinstitucional. PIB base año 2000.

Como se observa en las cifras del Balance Primario (Ilustración 3), el SPNF experimenta a partir del 2000 un superávit que alcanza su máximo en el 2008, pero que sufre una fuerte caída para el 2009 asociado a la crisis financiera mundial. En contraste el GNC obtuvo un superávit cercano al 1\% en el 2007 pero experimentó una brusca caída llevándolo al déficit en el 2009 del 1,1\% por la misma razón. Los resultados acumulados en el balance primario se reflejaron en la reducción del nivel de la deuda pública.

Ilustración 4. Balance Primario del Sector Público Colombiano

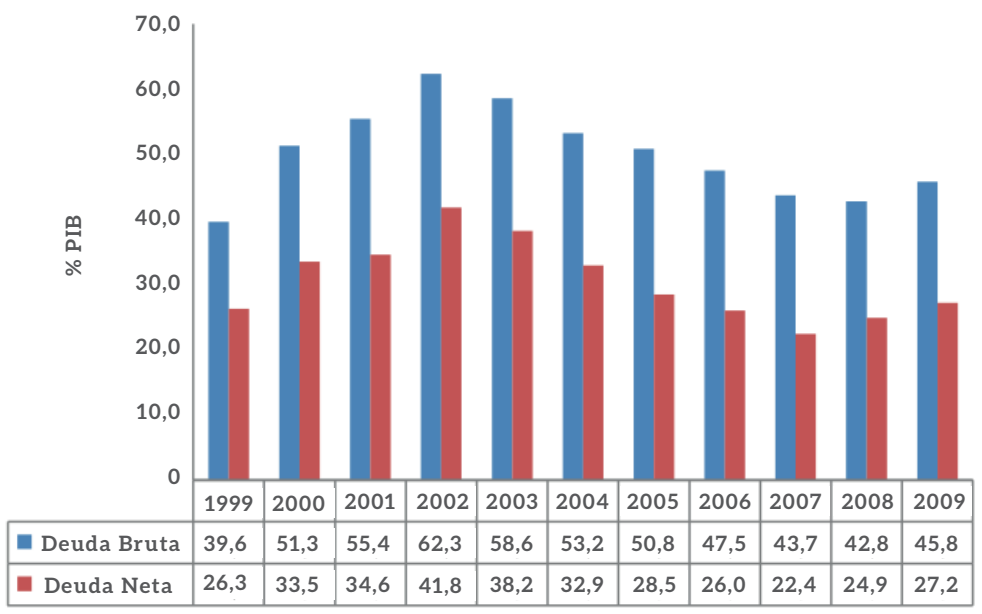

Fuente: Elaboración propia con base en datos de Comité Técnico Interinstitucional. PIB base año 2000. 
La deuda neta del SPNF corresponde a su deuda bruta menos los pasivos adquiridos entre las propias entidades públicas no financieras. También se descuentan los de activos financieros internos y externos del SPNF.

La deuda tanto bruta como neta ${ }^{3}$ del SPNF experimentó una disminución entre el 2002 y el 2008 al pasar de 62,3\% al 42,8\% la bruta, y la neta del 41,8\% al 24,9\%, respectivamente (Ilustración 4). Este resultado es explicado por menores tasas de inflación, tasas de interés más bajas y apreciación de la tasa de cambio. Sin dejar de lado el alto impacto que tuvo los elevados precios del petróleo, cuyo valor por barril llegó a sobrepasar los US\$100 en 2008.

\section{Ilustración 5. Deuda del Gobierno Nacional Central}

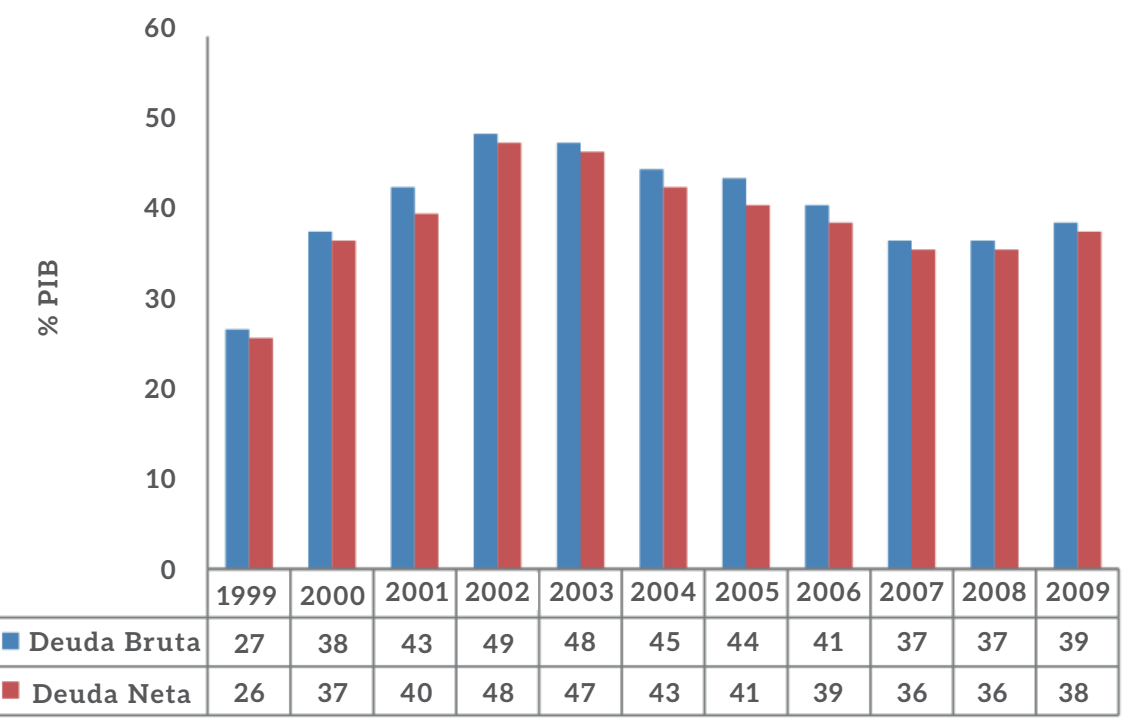

Fuente: Elaboración propia con base en datos Comité Técnico Interinstitucional. PIB base año 2000.

En las cuentas del GNC se observa una menor disminución de la deuda, tanto bruta como neta $^{4}$ entre 2002 y 2008 en relación con la del SPNF, al pasar del 49\% al 37\% de la deuda bruta. En el 2009 la deuda se incrementa en un 2\%, esto es explicado, entre otras cosas, por el bajo crecimiento económico experimentado por la economía, por el deterioro en el balance primario del 2009 que experimentó un déficit del 1,1\% del PIB.

Para dar cumplimiento a esta regla fiscal el gobierno de turno busca fortalecer ingresos principalmente a través de reformas tributarias que se convierten en un alto costo especialmente a la clase media y van en deterioro del crecimiento económico.

3. La deuda neta descuenta, de la primera, los pasivos entre las propias entidades del SPNF y los portafolios financieros que poseen las entidades en los mercados local y externo.

4. La deuda neta excluye los activos financieros que posee el GNC (depósitos en el Banco de la República y portafolios en el exterior). 


\section{SISTEMA GENERAL DE REGALÍAS (SGR)}

$\mathrm{Al}$ ser los recursos naturales no renovables una fuente de ingresos del Estado, se hace necesario entender las transformaciones que se presentan en el manejo de las regalías. La Constitución Política de 1991 en su artículo 332 establece que "el Estado es propietario del subsuelo y de los recursos naturales no renovables, sin perjuicio de los derechos adquiridos y perfeccionados con arreglo a las leyes preexistentes". El artículo 360 reconoce como beneficiario de las regalías directas a las entidades territoriales en las cuales se explotan y a los puertos marítimos o fluviales por donde se transportan los recursos naturales no renovables.

Por su parte el artículo 361 crea el Fondo Nacional de Regalías y determina los sectores de inversión, promoción de la minería, preservación del medio ambiente y proyectos regionales de inversión. El gobierno Santos propone modificar los objetivos, distribución, administración, ejecución y manejo de los ingresos de regalías. Es así como surge el Acto Legislativo 05 de 2011 que crea el Sistema General de Regalías (SGR) a través de la Ley 1530 de 2012, modificando el articulo 360 y 361 de la C.P, bajo el argumento de generar una distribución más equitativa de los recursos que percibe el estado por la explotación de sus recursos naturales no renovables, de tal forma que las regiones que experimentan índices de necesidades básicas insatisfechas sean las más beneficiadas.

La principal causa complementaria a lo anterior que llevan a esta transformación es corregir la concentración de las Regalías, debido a que solo el 17\% de la población ha venido recibiendo el $80 \%$ del total recaudado (Departamento Nacional de Planeación, 2013). De igual forma este sistema busca que los proyectos de inversión en su mayoría sean aprobados para generar impacto en las regiones. Para ello se crean los OCAD (Órganos Colegiados de Administración y Decisión) quienes definen la inversión y designan el ejecutor del proyecto.

El objetivo de equidad del SGR de acuerdo con la Contraloría General de la Nación (2017) se logró inmediatamente al pasar el Gini de regalías de 0,7 en 2010 a 0,47 en 2014 y los Municipios favorecidos de regalías pasaron de 655 en 2011 a 1.095 en 2017.

\section{REFORMAS TRIBUTARIAS}

La CP en su artículo 334 argumenta que el Estado debe garantizar la sostenibilidad fiscal, el mejoramiento de la calidad de vida de los habitantes, y distribución equitativa de las oportunidades para garantizar los objetivos del estado social de derecho. Para el cumplimiento de este mandato se debe hacer un análisis se la fuente de ingresos, siendo la más importante y más controvertida los impuestos.

Resulta sorprendente al analizar el tema la proliferación de reformas tributarias creadas en Colombia bajo el principal argumento de equilibrar las finanzas. Pareciese que los cálculos hechos por los gobiernos de turno para cumplir con sus compromisos no cuadra, y su único camino es por el lado del ingreso con más y más reformas tributarias. Desde el año 2005 hasta el 2015 se han presentado y aprobado seis reformas tributarias, en promedio se hace una reforma cada 18 meses, lo que ha llevado a tarifas muy dispersas, evasión, y se han convertido en un enredo para contribuyentes y en especial para inversionistas (Tabla 5). Muy por el contrario, estas reformas han castigado la generación de empleo, son regresivas e incumplen el principio de equidad horizontal, es decir, agentes de la misma capacidad económica siguen sin tributar de forma similar. 
Tabla 5.

Reformas Tributarias

\begin{tabular}{|c|c|c|}
\hline AÑO & LEY & ASPECTOS SOBRESALIENTES \\
\hline 2006 & 1111 & $\begin{array}{l}\text { Renta: reducción a la tarifa de renta de PJ al } 34 \% \text { en } 2007 \text { y } \\
33 \% \text { en } 2008 \text {. Aumento del } 30 \% \text { al } 40 \% \text { para la deducción por } \\
\text { inversión. Eliminación del impuesto de remesas. } \\
\text { IVA: algunos bienes pasan del } 10 \% \text { al } 16 \% \text {. } \\
\text { Otros: impuesto al patrimonio a partir del } 2007 \text { (tarifa del } 1.2 \% \\
\text { del patrimonio > } \$ 3.000 \text { millones. GMF de } 4 \text { x } 1000 \text { permanente. }\end{array}$ \\
\hline 2009 & 1370 & $\begin{array}{l}\text { Renta: reducción del } 40 \% \text { al } 30 \% \text { para la deducción en renta de } \\
\text { las inversiones en activos fijos productivos. } \\
\text { Otros: impuesto al patrimonio a partir del } 2011 \text { (tarifa del } 2.4 \% \\
\text { del patrimonio > } \$ 3.000 \text { millones, y del } 4.8 \% \text { para patrimonios > } \\
\$ 5.000 \text { millones) }\end{array}$ \\
\hline 2010 & 1430 & $\begin{array}{l}\text { Renta: eliminación de la deducción por inversión. } \\
\text { Otros: cerrar focos de evasión y eliminación progresiva del GMF, } \\
2 \text { x } 1000 \text { en } 2014,1 \text { x } 1000 \text { en } 2016 \text {, y desaparecerá en } 2018 \text {. } \\
\text { Eliminación de la sobretasa del } 20 \% \text { al consumo de energía } \\
\text { eléctrica del sector industrial. }\end{array}$ \\
\hline 2012 & 1607 & $\begin{array}{l}\text { Renta: creación del impuesto sobre la renta para la equidad } \\
\text { (CREE), como el aporte con el que contribuyen las sociedades y } \\
\text { personas jurídicas y asimiladas para el ICBF. } \\
\text { IVA: exclusión de algunos bienes susceptibles de para IVA. } \\
\text { Otros: servicios gravados con la tarifa del 5\%. Impuestos } \\
\text { descontables: a) impuesto sobre las ventas facturado al responsable } \\
\text { por la adquisición de bienes corporales muebles y servicios. B) el } \\
\text { impuesto pagado en la importación de bienes corporales muebles. }\end{array}$ \\
\hline
\end{tabular}

Renta: impuesto sobre la renta para personas naturales. Creación de dos sistemas presuntivos de determinación de la base gravable de impuesto mínimo alternativo (IMAN) e impuesto alternativo simple (IMAS). IVA: el primero de enero de 2013 solamente estará permitido cobrar tres valores de IVA: 0\% que se debe aplicar para toda la canasta familiar. 5\% para la medicina prepagada que antes estaba en 10\%. El 5\% también será para algunos alimentos procesados como embutidos. Otros: restaurantes que operan como franquicia y grandes cadenas pagarán un impuesto al consumo del 8\%. Quienes ganen más de \$3.600.000 deberán pagar el IMAN.

\begin{tabular}{ll}
\hline 2014 & $\begin{array}{l}\text { Mantuvo gravamen a los Movimientos Financieros (GMF) con } \\
\text { una tarifa de } 4 \text { x } 1000 \text { hasta el 2018, para iniciar su desmonte } \\
\text { gradual a partir de } 2019 .\end{array}$ \\
& $\begin{array}{l}\text { Creación del impuesto a la riqueza. } \\
\text { Creación de la sobretasa al CREE. }\end{array}$ \\
& IVA: aumento de 16 a 19\% \\
& Eliminación del CREE. Reducción de la tasa nominal del impuesto \\
& a las utilidades de las empresas. \\
& Eliminación del impuesto a la riqueza de personas naturales y jurídicas.
\end{tabular}

Fuente: Elaboración propia. 
Pese a que las reformas tributarias llevan implícita la equidad, lo que experimenta la economía es contradictorio: Colombia sobresale en América Latina y el mundo como uno de los países con mayor desigualdad medidos por el coeficiente Gini: el año 2010 el 1\% más rico concentra el 20.5\% del ingreso bruto, y entre 1993 y 2010 la participación del 1\% del ingreso más elevado se mantuvo constante entre los extremos de la población (Jimenez, 2015). De igual forma las recientes reformas tributarias 2012 y 2016 no contribuyeron a disminuir desigualdades de manera significativa, el Gini se redujo entre 2011 y 2012 en 0.009 puntos al pasar de 0.548 a 0.539. Después de entrar en funcionamiento la ley tributaria de 2012, la reducción a 2014 acumula solo un 0.001 pasando el Gini a 0.538 (Ilustración 6). La comisión de expertos resalta cómo en Colombia el 10\% más rico tiene ingresos 11 veces más altos que el 10\% más pobre (Valencia, 2015).

Ilustración 6. Coeficiente Gini 2010 - 2014

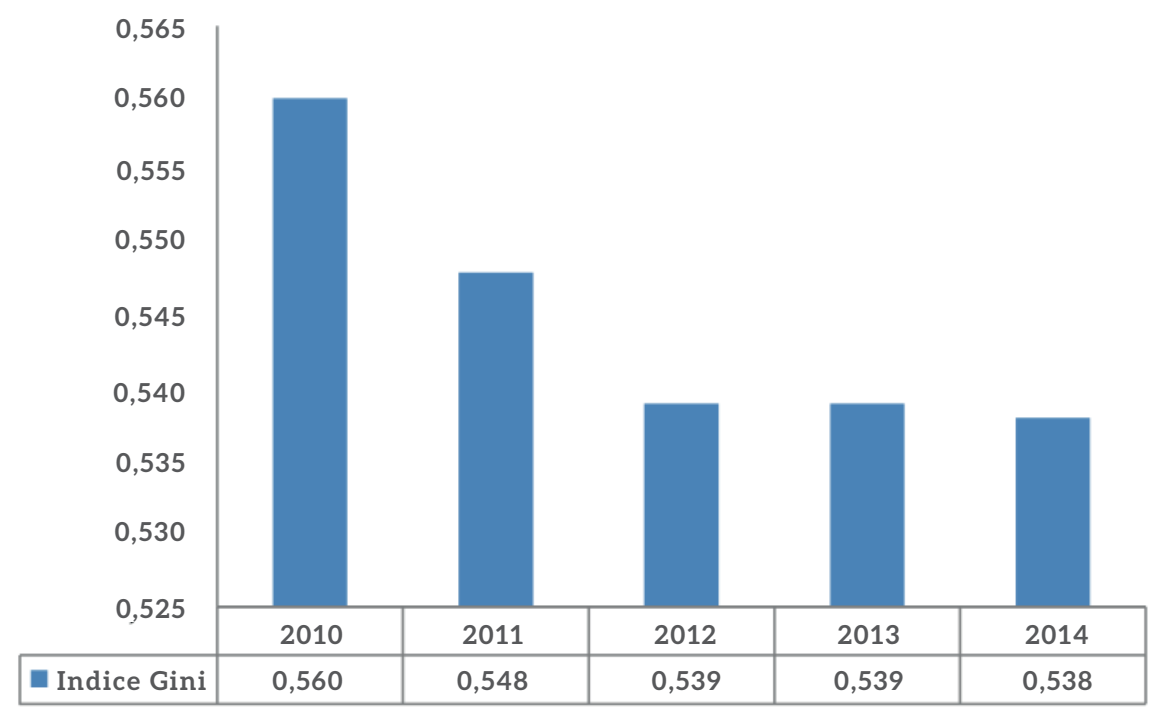

Fuente: Elaboración propia con base en datos del DANE.

Es importante aclarar que con la Ley 1739 del 2014 el Gobierno ordena la creación de una comisión de expertos para estructurar una nueva reforma tributaria que le dé cumplimiento a los principios de equidad, eficiencia y simplicidad. Para lo cual se deberá hacer una exhaustiva revisión de las normas tributarias encaminándose a una propuesta de reforma tributaria estructural para el Gobierno Nacional. En diciembre de 2015 la comisión arroja resultados que resumen el problema estructural del régimen tributario: bajo nivel de recaudo frente al potencial, limitada contribución a mejorar la distribución del ingreso, poca equidad horizontal, dificultad en la administración, no contribuye significativamente a la inversión, al empleo, al crecimiento y a la competitividad.

Cuenta con altos niveles de evasión, elusión y contrabando, que generan inequidad tributaria y desconfianza en la administración (Fedesarrollo, 2016). Resaltan como pese a que el recaudo tributario nacional paso del 9.7\% en 1998 al $15 \%$ en 2017, su crecimiento 
es muy lento, incumpliéndose las buenas intenciones de estas sucesivas reformas de aumentar recudo y dar cumplimiento a la regla fiscal. De los resultados de esta comisión surge un proyecto de reforma tributaria estructural que cumpla con los principios de progresividad, eficiencia, legalidad y certeza. Es así como nace la ley 1819 de 2016 con la esperanza para el gobierno de recaudar los recursos necesarios para frenar y disminuir el déficit fiscal que para el 2016 ya llego al 4\% del PIB. Lo cierto es que esta ley refleja regresividad al aumentar impuestos a la clase media y pobre y bajar impuestos a los más adinerados en Colombia.

Los gobiernos desechan otros argumentos para mejorar ingresos públicos como son: replantear exenciones tributarias innecesarias y que no cumplen su objetivo, mejorar el recauda del IVA que tiene una alta evasión junto con el impuesto de renta. Por otro lado, no aplica políticas que disminuyan la corrupción, y lo que se pierde por este flagelo se busca recuperar vía impuestos. Por tanto, las brechas y desigualdades sociales se podrían agudizar aún más.

\section{VOLATILIDAD DEL PRECIO DEL PETRÓLEO Y LAS FINANZAS PÚBLICAS}

Los tributos aplicados para actividades de extracción y producción de recursos naturales no renovables tienen características diferentes frente a los demás sectores, debido a que los recursos extraídos del suelo y del subsuelo no estarán disponibles posteriormente. Es así como la CEPAL (Arroyo, 2015) caracteriza las diferencias de este sector con los otros:

a) Es generador de altas utilidades en relación con otros.

b) El sector está sometido a un alto riesgo generado por la incertidumbre, especialmente la volatilidad de precios.

c) Lo invertido requiere un largo tiempo de producción para ser recuperado (costos hundidos).

d) Asimetría en la información entre inversionistas y el Gobierno.

e) Participación de multinacionales.

f) Poder en el mercado a través de una posición dominante sobre los precios.

Con estas características para abordar la incidencia de los precios del petróleo en las finanzas públicas de Colombia, se debe tener en cuenta el comportamiento del crecimiento de la economía y los factores que más han incidido en la fluctuación del PIB. Como se observa en la Ilustración 7, la economía colombiana registró el mejor desempeño en la historia del país entre 2005 y 2013, sobresale el alto crecimiento económico del 2006 y 2007 con un 6,7\% y 6,9\% respectivamente, explicado por la subida de manera considerable de los precios internacionales de los commodities, bajas primas de riesgo país en las economías emergentes y la amplia liquidez internacional que permitió un incremento en los flujos de inversión extranjera directa y de portafolio como bien lo explica el Banco de la República (Uribe, 2017). En el 2008 y 2009 la tasa de crecimiento del PIB se desaceleró como consecuencia de la crisis financiera internacional que golpeó con fuerza al comercio internacional, y la confianza inversionista. En el periodo 2011-2013 la economía retorna a un buen desempeño económico gracias a, explicado principalmente, el incremento de los precios del petróleo que superan la barrera de los US $\$ 110$ el barril. En el 2014 la caída acelerada del precio del petróleo explica esta tendencia a la disminución del crecimiento económico y sus implicaciones en los ingresos del GNC, en la caída de las exportaciones y en el aumento del déficit tanto fiscal como en la cuenta corriente de la balanza de pagos. 


\section{Ilustración 7. Crecimiento económico colombiano}

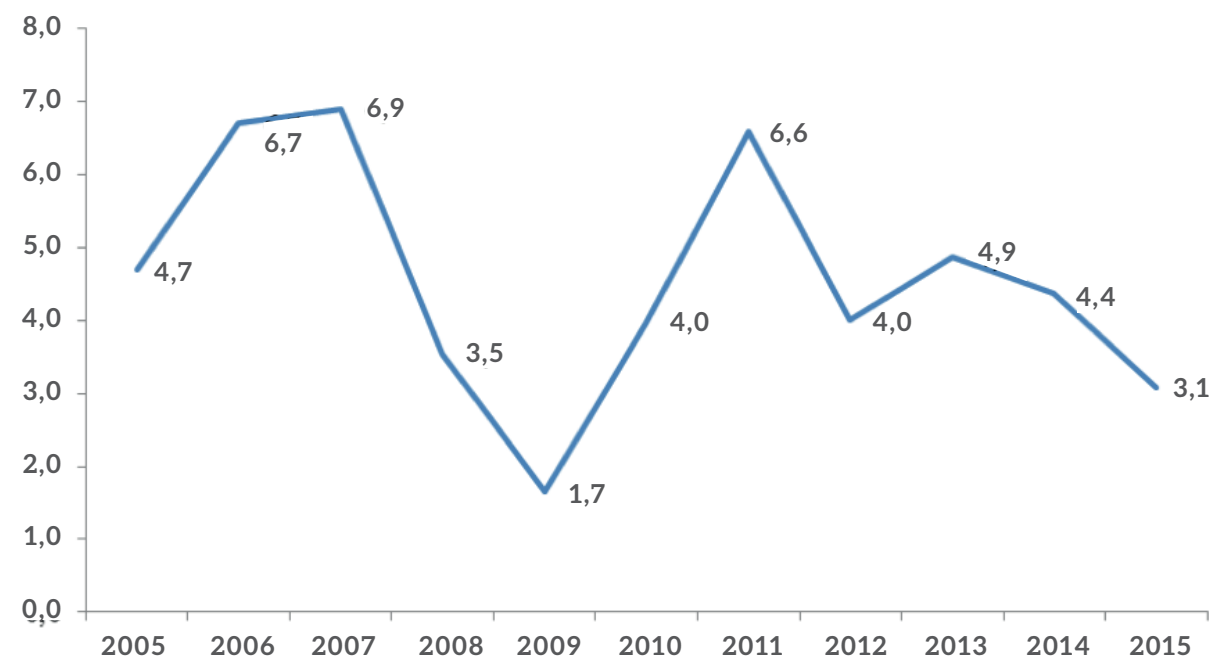

Fuente: Elaboración propia con base en datos del Banco Mundial.

Indudablemente, la caída de los precios del petróleo (renta + CREE petroleros y dividendos de Ecopetrol) ha representado el choque más significativo para la economía colombiana. Sin embargo, esto plantea un desafío para la política fiscal, después de participar en el 2005 con un 1,43\% del PIB en los ingresos de la Nación, teniendo un crecimiento moderado hasta llegar al 2,2\% en 2008 y posteriormente caer de manera abrupta en el 2010 a un 0,9\% del PIB en los ingresos de la Nación, se pasa a un 3,3\% del PIB en el 2013 (año anterior al inicio de la caída de los precios del petróleo), lo que se considera un crecimiento significativo para las finanzas públicas (Cárdenas, 2016). Durante ese año ya estaba en marcha la reforma tributaria aprobada en diciembre de 2012. La caída del precio del petróleo golpea fuertemente estos ingresos del GNC llevándolos en 2015 al 1,2\% del PIB, esto es explicado por la pérdida de más de US\$17mil millones en exportaciones minero-energéticas (Fedesarrollo, 2018).

Gracias a los altos ingresos petroleros recibidos por el Gobierno se pudo reducir el déficit fiscal de cerca del 4,5\% en el 2004 al 2,3\% en el 2013. Con la caída en el crecimiento económico y en los precios del petróleo a partir del segundo semestre del 2014, el Gobierno busca amortiguar este impacto negativo a las finanzas creando la reforma tributaria del 2014 para financiar el faltante identificado en el presupuesto del 2015 y poniendo en marcha un programa de austeridad en el gasto (Ilustración 8). 


\section{Ilustración 8. Déficit Fiscal}

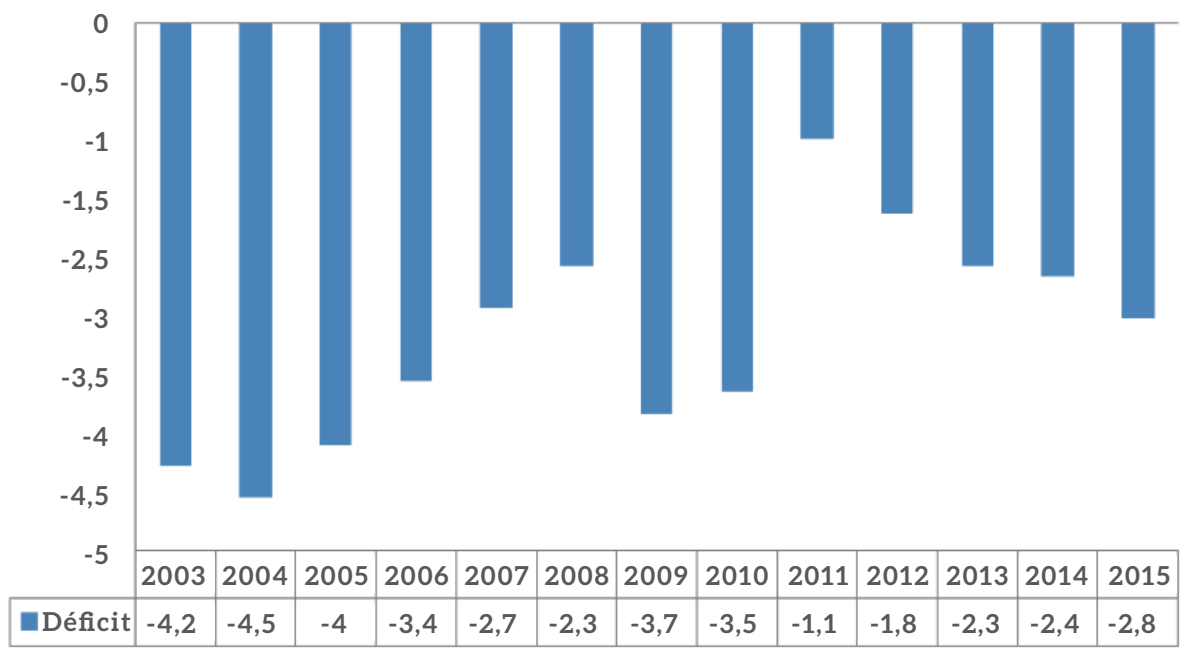

Fuente: Elaboración propia con base en Ministerio de Hacienda y Crédito Público

En lo que respecta a la austeridad en el gasto se aumentan los ingresos tributarios no petroleros para distribuir el peso del ajuste por el choque petrolero, se reduce el gasto sin afectar considerablemente el gasto social, y un 0,8\% del PIB del 2015 se aplazó para el año siguiente (Cárdenas, 2016). Esto para garantizar la sostenibilidad de las finanzas públicas y asegurar el cumplimiento del objetivo de la regla fiscal: llegar a un déficit total estructural del 1\% del PIB en 2022.

\section{CONCLUSIONES Y RECOMENDACIONES}

El Gobierno no es claro en su reorientación del gasto público respecto a su política de austeridad, y el camino más fácil es la aplicación de reformas tributarias que están conduciendo a ampliar la brecha ya existente entre ricos y pobres al recaer los gravámenes sobre la clase media, principalmente.

Al convertirse SGP en el eje central de la inversión social de Colombia se hace necesario una reforma dado que las brechas regionales no se han cerrado con este sistema y las disminuciones de pobreza no han sido homogéneas como bien lo explica Ocampo (2017): Mientras que entre el 2003 y el 2017, la pobreza monetaria se redujo en 36 puntos porcentuales (p. p.) en Cundinamarca y Boyacá, solo disminuyó en 10,5 p. p. en Chocó, y 5,7 en La Guajira. La pobreza extrema se redujo en 27,8 p. p. en Boyacá, pero aumentó en 6 p. p. en La Guajira. Asimismo, a pesar de tener cobertura universal en educación primaria, hay 60 municipios donde la cobertura en educación primaria no alcanzaba el 50 por ciento en el 2016.

El cambio constitucional respecto al manejo de regalías bajo el argumento de que son de la Nación y no de las regiones debe estar acompañado de la calidad de las instituciones, ya que la riqueza de los recursos naturales puede generar pérdida o ganancia respecto al 
crecimiento como lo sugiere Halvar Mehlum (Mehlum, 2006). Calidad que determina si los recursos naturales contribuyen a la creación de riqueza y mayor bienestar, o si por el contrario su explotación y uso se orienta a instituciones de naturaleza rentista alejadas del mejoramiento y el bienestar social.

La fuerte caída en los precios del petróleo ha traído una disminución en la inversión pública, una escases de divisas, un encarecimiento en los créditos en moneda extranjera conllevando a una inestabilidad financiera que deteriora los indicadores económicos positivos experimentados en los últimos años por la economía Colombiana. Se podría afectar los niveles de empleo invirtiendo la tendencia de pobreza, pasando de una disminución a un incremento de la misma.

Elpocodinamismoexperimentadopor los sectoreseconómicos frenteal aprovechamiento en el aumento de la tasa de cambio entre el 2014 y el 2015 demuestra que muchos de ellos cambiaron su actividad industrial a comercial por la apreciación del peso frente al dólar experimentada a partir del 2002 hasta mediados del 2014 con importaciones mucho más económicas y rentables. Lo que lleva, según algunos expertos, a que el país experimente síntomas de enfermedad holandesa, es decir, el sector industrial pierde dinamismo, demostrándose que no existían políticas públicas claras para que la economía desarrollara un sector industrial y manufacturero competitivo y sólido que se beneficiara de la depreciación del tipo de cambio que se experimenta hoy como consecuencia, principalmente, de la baja de los precios del petróleo.

\section{REFERENCIAS BIBLIOGRAFICAS}

Aghón, G. (2001). Desarrollo económico local y descentralización fiscal en América Latina: Análisis comparativo. Santiago de Chile: CEPAL.

Arroyo, A. (2015). Impacto fiscal de la volatilidad del precio del petróleo en América latina y el Caribe. Santiago de Chile: CEPAL, Naciones Unidas.

Cárdenas, M. (2016). Situación fiscal de Colombia: ¿En qué consiste la austeridad inteligente? Economía Colombiana, 345.

Departamento Nacional de Planeación. (2013). Sistema General de Regalías.

Escobar-Espinoza, A., Guevara-Castañeda, D., \& Uribe-Veloza, M. (2017). Modelos Computacionales y Análisis de la Política Económica en Colombia. Panorama Económico, 25(4), 535-558. doi:https://doi.org/10.32997/24630470-vol.25-num.4-2017-2088

Fedesarrollo. (2016). Comisión de Expertos para la Equidad y Competitividad Tributaria. Informe final presentado al Ministro de Hacienda y Crédito Público. Bogotá: Fedesarrollo. Obtenido de http://hdl.handle.net/11445/3284

Fedesarrollo. (2018). Comisión del gasto y la inversión pública. Informe final. Bogota: Fedesarrollo. Obtenido de https://www.fedesarrollo.org.co/sites/ default/files/LIB2017COMISION.pdf 
Flores-Tapia, C., \& Flores-Cevallos, K. (2017). Impactos económicos inducidos por la demanda final en sectores estratégicos para el cambio de la estructura productiva del Ecuador. Panorama Económico, 25(3), 443-458. DOI: https:// doi.org/10.32997/2463-0470-vol.25-num.3-2017-2085

Jimenez, J. P. (2015). Desigualdad, concentración del ingreso y tributación sobre las altas rentas en América Latina - CEPAL. Santiago de Chile: Naciones Unidas.

Mehlum, H. (2006). Institutions and the resource course. Oslo: Department of Economics - University of Oslo.

Ministerio de Hacienda y Crédito Público. (2009). 10 Años de transformación fiscal territorial en Colombia. Bogotá, Colombia: Ministerio de Hacienda y Crédito Público.

Missaglia, M. (2015). ¿Se pueden aplicar las ideas Keynesianas al largo plazo? Unas reflexiones teóricas y un modelo ilustrativo. Panorama Económico, 23, 17-30. DOI: https://doi.org/10.32997/2463-0470-vol.23-num.1-2015-1380

Ramirez, H. (2008). Finanzas Públicas. Universidad Libre de Colombia.

Rodríguez Estupiñan, G. (2012). Veinte Años de Constitución: ¿Avance o retroceso fiscal? Economicas CUC, 33(1), 283-296. Obtenido de http://hdl. handle.net/11323/1342

Steiner, R. (2014). Los beneficios de la regla fiscal. Fedesarrollo.

Uribe, J. (2017). Informe de gestión 2005-2016. Banco de la República . Bogotá D.C.: Banco de la República.

Valencia, M. R. (2015). Fin del auge petróleo y crisis económica colombiana: causas, responsables y propuestas - Justicia Tributaria. Cedetrabajo.

Vergara-De la Ossa, R., Londoño-Vega, C., Pérez-Benítez, N., \& Torres-Castellar, R. (2015). La adopción de las Normas Internacionales de Información Financiera en Colombia. Panorama Económico, 23, 119-132. DOI: https:// doi.org/10.32997/2463-0470-vol.23-num.1-2015-1382 